OPEN ACCESS

Edited by:

Roberto Canitano, Siena University Hospital,

Reviewed by: Giacomo Vivanti,

Drexel University, United States

Sarah Karalunas,

Oregon Health \& Science University,

United States

Peter G. Enticott,

Deakin University, Australia

${ }^{*}$ Correspondence:

Adam J. Guastella

adam.guastella@sydney.edu.au

Specialty section:

This article was submitted to Child and Adolescent Psychiatry,

a section of the journal

Frontiers in Psychiatry

Received: 20 April 2019 Accepted: 19 September 2019 Published: 11 November 2019

Citation:

Demetriou EA, DeMayo MM and Guastella AJ (2019) Executive

Function in Autism Spectrum Disorder: History, Theoretical Models,

Empirical Findings, and

Potential as an Endophenotype.

Front. Psychiatry 10:753.

doi: 10.3389/fpsyt.2019.00753

\section{Executive Function in Autism Spectrum Disorder: History, Theoretical Models, Empirical Findings, and Potential as an Endophenotype}

\author{
Eleni A. Demetriou, Marilena M. DeMayo and Adam J. Guastella* \\ Autism Clinic for Translational Research, Brain and Mind Centre, Faculty of Medicine and Health, Children's Hospital \\ Westmead Clinical School, University of Sydney, Sydney, NSW, Australia
}

This review presents an outline of executive function (EF) and its application to autism spectrum disorder (ASD). The development of the EF construct, theoretical models of EF, and limitations in the study of EF are outlined. The potential of EF as a cognitive endophenotype for ASD is reviewed, and the Research Domain Criteria (RDoC) framework is discussed for researching EF in ASD given the multifaceted factors that influence EF performance. A number of executive-focused cognitive models have been proposed to explain the symptom clusters observed in ASD. Empirical studies suggest a broad impairment in EF, although there is significant inter-individual variability in EF performance. The observed heterogeneity of EF performance is considered a limiting factor in establishing EF as a cognitive endophenotype in ASD. We propose, however, that this variability in EF performance presents an opportunity for subtyping within the spectrum that can contribute to targeted diagnostic and intervention strategies. Enhanced understanding of the neurobiological basis that underpins EF performance, such as the excitation/inhibition hypothesis, will likely be important. Application of the RDoC framework could provide clarity on the nature of EF impairment in ASD with potential for greater understanding of, and improved interventions for, this disorder.

Keywords: executive function, autism spectrum disorder, neurobiology, excitation/inhibition, GABA, endophenotype

\section{PREFACE}

Autism spectrum disorder (ASD) is a neurodevelopmental condition defined by difficulties in social communication and interaction, as well as restricted, repetitive patterns of behavior, interests, or activities (1). The social communication domain includes difficulties in reciprocal social interaction (2); deficits in non-verbal social communication $(3,4)$; and impairments in ability to develop, maintain, and understand relationships (5). Symptoms associated with the restricted and repetitive behavior domain manifest across motor, verbal, non-verbal, and sensory modalities (6). Observed behaviors in the restricted and repetitive domain may include motor stereotypies, echolalia, insistence on sameness, ritualized behaviors, narrow interests, and hyper- or hypo-reactivity to sensory stimuli (1). 
A number of cognitive models $(5,7)$ have been proposed to explain difficulties observed across the life span in ASD $(8,9)$. One such model, the executive dysfunction hypothesis, focused on explaining the atypical executive function (EF) processes in $\operatorname{ASD}(10,11)$. This model developed following observation of difficulties in set shifting (ability to shift mindset to new concepts), response inhibition (ability to inhibit a dominant response), and working memory (retaining and updating information in short-term memory) (12). Early research focused on set shifting (13) and its relationship to stereotypic and repetitive behaviors (14). Findings were interpreted to show a link between cognitive rigidity and the perseverance to routines and stereotypies observed in ASD (15). Increasingly, however, research implicates a broader influence of EF on the ASD phenotype. These include impacts of EF on social cognition (16, 17), mental health (18), disability $(19,20)$, and lifelong functioning outcomes (21). Overall, findings on EF in ASD suggest a broad impairment $(22,23)$ that is characterized by marked heterogeneity (24). The study of EF in ASD has focused primarily on investigating discrete EF constructs or domains (25). This is in contrast to the wider range of EF models developed in response to neurotypical development (26-28).

This paper presents a discussion of EF research in ASD, an overview of EF models drawn from typical and atypical development, and their potential contribution to the study of ASD. Factors that may moderate research outcomes of EF in ASD are also discussed. These include measurement issues of the EF construct, moderator influences on EF, and differences in the developmental trajectory of EF in ASD. Finally, a research model based on the efficacy of EF as an endophenotype is proposed within the research framework of Research Domain Criteria (RDoC) (29).

\section{CONCEPTUALIZATION OF EXECUTIVE FUNCTION}

The term EF was first proposed in the mid-20 ${ }^{\text {th }}$ century to explain functions associated with the frontal cortex (30). Frontal lobes were of interest following case studies, such as Phineas Gage (31), where it was observed that frontal lobe damage was associated with impairment of discrete functions, such as planning, organization, and self-regulation, even though general intellectual functioning remained mostly intact. This observation and subsequent case studies (32) led to conclusions that the frontal lobes have a primary role in organizing higherorder functions (33). Much of the subsequent research of EF focused primarily on the frontal lobes and functions associated with them $(34,35)$.

EF has been broadly defined as the overarching regulation of goal-directed, future-oriented, higher-order cognitive processes $(28,36-38)$. Although there is general agreement on the broad concept of EF, the theoretical models and processes that may underpin it vary considerably. Models of EF draw on different theoretical paradigms and include cognitive, clinical, behavioral, and neurobiological frameworks (39). This has, in part, contributed to the divergent frameworks of theorized models and mechanisms (38). In this paper, we present an overview of EF models and distinguish between them based on the level of analysis and measurement of the EF construct. Models are classified based on behavioral, cognitive, neuroanatomical, and neural measurement frameworks. Tables 1 and 2 summarize key features of these EF models and associated measurement tools.

\section{Cognitive and Behavioral Models of EF}

A number of cognitive models of EF have discriminated between automatic and controlled cognitive processes (78) that are regulated by discrete attentional systems. Models focusing on attentional control included those proposed by Baddeley (79), Posner (42), and Shallice (80). Executive attention was attributed a regulatory role that facilitated focus on salient cues and regulated EF processes (Table $\mathbf{1}$ ).

Many researchers adopted a fractionated approach in order to distinguish between individual EF processes or domains (EFs) $(12,81)$ (Table 2). The number of discrete EFs reported on in the literature has ranged from 2 (82) to more than 30 (38). The three most commonly reported or core EFs are set shifting, response inhibition, and working memory $(12,38)$. Different levels of complexity have been proposed for EFs. For example, it is suggested that the three core EFs above, contribute to the higher-order EFs such as reasoning, planning, and problem solving (81). The Delis-Kaplan model (50) was developed in response to clinical observations of functions sensitive to frontal lobe damage and proposed nine EFs (Table 1). Until recently, most research focused on the study of a combination of the above core and higher order EFs. These are broadly referred to as cool EFs, defined as EF processes that are conducted independently of contextual framework or affective and motivational influences (83).

More recently, a distinction has been drawn between cool EFs and other cognitive processes, defined as hot EFs (84). Hot EFs are defined as the cognitive processes mediated by affective and motivational demands (76). They represent goal-oriented behaviors, moderated by personal appraisal of the affective or motivational significance of the stimuli. Hot EFs are increasingly studied in ASD cohorts (85) and are particularly relevant for this group because of their likely influence on behavioral regulation (86). Behavioral regulation is an integral component of models proposed by Stuss (28, 87), Barkley (37), and Gioia (48). Each of these models adopts a multifactorial approach that integrates cool and hot EFs as well as behavior regulatory control to varying degrees.

The model proposed by Stuss $(28,87)$ integrates cool EFs (task setting and monitoring) and non-EFs frontal lobe processes (energization, behavioral/emotional self-regulation, and metacognition). Energization refers to processing speed when completing cognitive tasks. Behavioral/emotional selfregulation is in part dependent on activation of EFs (task setting and monitoring). Metacognition has a higher-order supervisory role in integrating all EFs and non-EFs processes towards goal attainment. 
TABLE 1 | Summary of EF models.

\begin{tabular}{|c|c|c|c|c|c|}
\hline EF model & EF construct(s) & EF mechanism & $\begin{array}{l}\text { Neurobiological } \\
\text { underpinnings }\end{array}$ & Predictions & Interventions \\
\hline \multicolumn{6}{|l|}{ Unifactor models } \\
\hline $\begin{array}{l}\text { Working memory } \\
\text { (40) }\end{array}$ & $\begin{array}{l}\text { Central executive } \\
\text { Central executive } \\
\text { fractionated to component } \\
\text { parts of } \\
\text { - Focused attention } \\
\text { - Divided attention } \\
\text { - Attention switching } \\
\text { - Interface with long-term } \\
\text { memory (episodic buffer) }\end{array}$ & $\begin{array}{l}\text { Attentional focus, } \\
\text { storage, and decision } \\
\text { making } \\
\text { Central executive } \\
\text { regulates } \\
\text { information control to } \\
\text { the working memory } \\
\text { component process } \\
\text { of the phonological } \\
\text { loop and visuospatial } \\
\text { sketchpad } \\
\text { Information integrated } \\
\text { in episodic buffer and } \\
\text { interfaced with long-term } \\
\text { memory }\end{array}$ & $\begin{array}{l}\text { Baddeley ( } 40 \text { ) noted } \\
\text { that this has been } \\
\text { guided by observations } \\
\text { of patients with } \\
\text { neurobiological damage } \\
\text { but does not specify } \\
\text { distinct neurobiological } \\
\text { mechanisms }\end{array}$ & $\begin{array}{l}\text { Model viewed as a } \\
\text { homunculus approach } \\
\text { predicting complex } \\
\text { behavior regulation } \\
\text { Impaired mechanisms } \\
\text { would lead to broad } \\
\text { behavioral dysregulation }\end{array}$ & $\begin{array}{l}\text { Working memory } \\
\text { assessment } \\
\text { system for } \\
\text { children with a } \\
\text { practical guide } \\
\text { for cognitive } \\
\text { interventions } \\
(40,41)\end{array}$ \\
\hline Attentional control (42) & Executive attention & $\begin{array}{l}\text { Fractionation of } \\
\text { attentional system into } \\
\text { components of } \\
\text { - Orienting } \\
\text { - Alerting } \\
\text { - Cognitive } \\
\text { Cognitive attention } \\
\text { responsible for } \\
\text { regulation of cognitive } \\
\text { functions }\end{array}$ & & $\begin{array}{l}\text { Impaired mechanisms } \\
\text { would lead to broad } \\
\text { behavioral dysregulation }\end{array}$ & $\begin{array}{l}\text { Cognitive } \\
\text { remediation } \\
\text { programs } \\
\text { to improve } \\
\text { attentional control }\end{array}$ \\
\hline $\begin{array}{l}\text { Supervisory Attentional } \\
\text { system } \\
\text { (43) }\end{array}$ & $\begin{array}{l}\text { Executive attention } \\
\text { Inhibitory control }\end{array}$ & $\begin{array}{l}\text { Distinction is made } \\
\text { between routine or } \\
\text { habituated actions } \\
\text { versus non-routine } \\
\text { actions } \\
\text { Non-routine actions } \\
\text { require the individual } \\
\text { to disengage from } \\
\text { habituated behavior } \\
\text { patterns and make a } \\
\text { novel response } \\
\text { The supervisory } \\
\text { attentional system } \\
\text { exerts supervisory } \\
\text { control in novel } \\
\text { situations where routine } \\
\text { or previously learned } \\
\text { behaviors must be } \\
\text { inhibited }\end{array}$ & & $\begin{array}{l}\text { Impaired mechanisms } \\
\text { would lead to broad } \\
\text { behavioral dysregulation } \\
\text { including perseverative } \\
\text { behaviors, distractibility, } \\
\text { and apathy due to } \\
\text { disrupted inhibitory } \\
\text { control (44) }\end{array}$ & $\begin{array}{l}\text { Cognitive } \\
\text { remediation } \\
\text { programs } \\
\text { to improve } \\
\text { attentional control }\end{array}$ \\
\hline \multicolumn{6}{|l|}{ Multifactorial models } \\
\hline $\begin{array}{l}\text { Unity and diversity } \\
\text { (12) }\end{array}$ & $\begin{array}{l}\text { Common factor (response } \\
\text { inhibition) } \\
\text { Set shifting } \\
\text { Updating/working memory }\end{array}$ & $\begin{array}{l}\text { Maintain and manage } \\
\text { goals } \\
\text { Task switching } \\
\text { Updating and replacing } \\
\text { irrelevant information in } \\
\text { working memory }\end{array}$ & $\begin{array}{l}\text { Genetic underpinning } \\
\text { of EF common factor } \\
\text { (45) } \\
\text { Frontal lobe } \\
\text { involvement for } \\
\text { common EF factor; } \\
\text { prefrontal cortex } \\
\text { and basal ganglia } \\
\text { circuitry for shifting } \\
\text { factor; basal ganglia } \\
\text { mediated updating } \\
\text { process (46) } \\
\text { Mediated by GABA } \\
\text { glutamate neural } \\
\text { mechanisms (47) }\end{array}$ & & $\begin{array}{l}\text { Pharmacological } \\
\text { interventions } \\
\text { targeting GABA } \\
\text { and cognitive } \\
\text { interventions } \\
\text { addressing the } \\
\text { specific cognitive } \\
\text { mechanisms }\end{array}$ \\
\hline
\end{tabular}


TABLE 1 | Continued

\begin{tabular}{ll}
\hline EF model & EF construct(s) \\
& \\
\hline Fractionated models of EF & \\
Diamond's model of $\mathrm{EF}_{1}$ & Set shifting \\
Delis-Kaplan model of $\mathrm{EF}_{2}$ & Response inhibition $_{1,2}$ \\
& Working memory $_{1,2}$ \\
& Planning $_{1}$ \\
& Problem solving $_{1,2}$ \\
& Reasoning $_{1,2}$ \\
& Fluency $_{2}$ \\
& Categorical processing $_{2}$ \\
& Verbal abstraction $_{2}$ \\
&
\end{tabular}

Models linking EF and behavioral regulation Stuss' model of EF (28)
Task setting Task monitoring

\begin{abstract}
"the use of self-directed actions so as to choose goals and to select, enact and sustain actions across time towards those goals usually in the context of others often relying on social and cultural means for the maximization of one's long-term welfare as the person defines that to be" (37)
\end{abstract}

EF mechanism

Neurobiological
underpinnings

Regulation of discrete EF cognitive processes

\section{Neurobiological underpinnings not specifically defined in the model but supported by findings of neuroanatomical localization of discrete domains and functional connectivity between brain regions The Delis-Kaplan model draws on observations of patients with prefrontal lobe injuries, and emphasis is therefore on the prefrontal lobes}

EFs interacting with non-EF domains of: Energization Behavioral/emotional self-regulation Metacognition
Task setting: left lateral frontal cortex

Task monitoring: right lateral frontal cortex Behavioral/emotional regulation: orbitofrontal cortex

Energization: superior medial prefrontal cortex Metacognition: frontal poles

Development of

five EFs draws on

Luria's model and observations of patients with prefrontal lobe injuries (37)
Predictions

Interventions

$\begin{array}{ll}\text { Impairment in discrete } & \text { Cognitive } \\ \text { EF processes } & \text { remediation } \\ & \text { interventions } \\ & \text { addressing each } \\ & \text { EF domain } \\ & \text { Pharmacological } \\ \text { interventions } & \text { addressing neural } \\ \text { substrates }\end{array}$

Impairment in EF processes of task setting and monitoring leading to specific deficits and overall dysregulation due to association with behavioral/emotional self-regulation

Cognitive remediation interventions targeting EF processes and potentially pharmacological interventions targeting underpinning neural mechanisms

$\begin{array}{ll}\text { Impaired regulation of } & \text { Intervention } \\ \text { each of the domains } & \text { strategies may } \\ \text { leading to overall } & \text { be addressing } \\ \text { difficulties in goal } & \text { distinct underlying } \\ \text { attainment } & \text { cognitive } \\ & \text { components } \\ & \text { of each of the } \\ & \text { self-management } \\ & \text { domains }\end{array}$
of EF Self-directed attention (self-awareness and monitoring)

Self-restraint (inhibition) Self-directed sensing (non-verbal working memory) Self-directed speech (verbal working memory) Self-directed emotions and motivations

Self-directed play (planning and problem solving)

\begin{tabular}{|c|c|}
\hline Gioia's model of EF & $\begin{array}{l}\text { Self-regulation of behavior } \\
\text { based on "selection, } \\
\text { initiation, execution and } \\
\text { monitoring of cognition } \\
\text { and behaviour," p.1 (48) }\end{array}$ \\
\hline
\end{tabular}

Self-regulation of behavior initiation, execution and and behaviour," p.1 (48)

\begin{tabular}{|c|c|c|}
\hline $\begin{array}{l}\text { "Frontal systems" } \\
\text { regulation of EF } \\
\text { processes } \\
\text { Emphasis on the } \\
\text { regulatory control by } \\
\text { the frontal lobes of } \\
\text { cortical and subcortical } \\
\text { areas, p.3 (48) }\end{array}$ & $\begin{array}{l}\text { Impaired regulation of } \\
\text { each of the domains }\end{array}$ & $\begin{array}{l}\text { Intervention } \\
\text { strategies may } \\
\text { be addressing } \\
\text { distinct underlying } \\
\text { cognitive } \\
\text { components } \\
\text { of each of the } \\
\text { self-management } \\
\text { domains }\end{array}$ \\
\hline
\end{tabular}

(Continued) 
TABLE 1 | Continued

\begin{tabular}{|c|c|c|c|c|c|}
\hline EF model & EF construct(s) & EF mechanism & $\begin{array}{l}\text { Neurobiological } \\
\text { underpinnings }\end{array}$ & Predictions & Interventions \\
\hline \multicolumn{6}{|c|}{ Neurobiological models of EF } \\
\hline Luria's model & $\begin{array}{l}\text { Complex information } \\
\text { processing }\end{array}$ & $\begin{array}{l}\text { Functional integration of } \\
\text { three brain functional units } \\
\text { First and second } \\
\text { functional units: } \\
\text { responsible for alertness } \\
\text { and sensory information } \\
\text { processing } \\
\text { Third functional unit: } \\
\text { responsible for regulation } \\
\text { and execution of behavior }\end{array}$ & $\begin{array}{l}\text { First and second } \\
\text { functional units controlled } \\
\text { by parietal, temporal, } \\
\text { and occipital lobes } \\
\text { Third functional unit } \\
\text { regulated by the frontal } \\
\text { lobes }\end{array}$ & $\begin{array}{l}\text { "Frontal lobe syndrome" } \\
\text { (49) } \\
\text { Disinhibition } \\
\text { Inability to follow } \\
\text { sequence of action } \\
\text { Repetitive motor } \\
\text { movements }\end{array}$ & \\
\hline E/I hypothesis & & GABA/glutamate balance & $\begin{array}{l}\text { Neural circuitry cortical } \\
\text { and subcortical areas }\end{array}$ & $\begin{array}{l}\text { Impairment in discrete } \\
\text { EFs depending on } \\
\text { neuroanatomical } \\
\text { localization }\end{array}$ & $\begin{array}{l}\text { Pharmacological } \\
\text { interventions }\end{array}$ \\
\hline
\end{tabular}

EF, executive function; E/l, excitation/inhibition; GABA, $\gamma$-aminobutyric acid.

Barkley's model (88) is defined by five EF factors that regulate behavior towards achieving future goals (37). The five EF factors were empirically derived from behavioral ratings, primarily in cohorts with attention deficit hyperactivity disorder (ADHD). They are described as an individual's ability to manage time, organize and problem-solve, exercise restraint, self-motivate, and regulate emotion (37). The five EF factors are surmised to be influenced by external (cultural/societal factors) and intra-individual processes (88).

Gioia and associates (48) utilized the umbrella definition of self-regulatory process of EF that involves the "selection, initiation, execution and monitoring of cognition and behaviour" (p. 1). Within this framework, they developed a behavioral assessment that utilizes self- and/or informant ratings and draws on cool EFs (e.g. response inhibition, set shifting, and working memory) and behavioral control (e.g. emotional control).

\section{Neurobiological and Neural Models of EF}

Alexander Luria was one of the first researchers to introduce a model based on neurobiological processes (26) suggesting the broader engagement of various brain regions. In this model, frontal lobes were conceptualized as the regulatory area directing complex problem solving. Damage to the frontal lobes was associated with the frontal lobe syndrome (49), characterized by disinhibition, inability to follow a sequence of instructions, and repetitive motor movements.

Advancements in neuroimaging techniques have placed increasing focus on neuroanatomical localization of EF processes primarily within frontal cortical regions. Localization of cool EF processes has been associated primarily with the dorsolateral prefrontal cortex (PFC), while the top-down processes that regulate hot EFs are linked to the orbitofrontal or ventromedial prefrontal cortex. Some cognitive models also propose specific neuroanatomical correlates of EF. For example, for Stuss' model (87) it was proposed that the task setting and monitoring EFs are localized in the left and right lateral frontal cortex, respectively, while behavioral/emotional regulation corresponds with the localization of hot EFs in the orbitofrontal cortex. Energization is reported to be mediated by the superior medial prefrontal cortex, while metacognition is guided by the frontal poles (87).

The identification of these regional contributions, while valuable, does not encapsulate the broad cortical systems that are being recognized as significant in the neural processes that underlie EF processes (89). Building on the neuroanatomical localization of EF, connectivity models focus on neural circuitry between cortical regions and may present a more integrated approach in the study of EF.

Neuroimaging studies identified that discrete EFs are linked to broader brain networks including the areas within the prefrontal cortex. For example, set shifting was associated with activity of the lateral prefrontal cortex, anterior cingulate cortex, and inferior parietal lobule (52). Set switching task was associated with involvement of the prefrontal cortex and frontoparietal areas of the brain $(52,90)$. An extended brain network connectivity between dorsal and ventral brain networks was observed in fluency tasks including activation in the inferior frontal gyrus and left dorsolateral prefrontal cortex (34). A differentiation between dorsal and ventral brain networks was observed between phonemic and semantic fluency tasks, respectively (61). Similarly, extended brain network involvement is reported during completion of planning tasks including activation of the dorsolateral prefrontal cortex, the anterior and posterior cingulate areas, and the parietal cortex (91). Activation of frontal regions during working memory tasks included activation of the bilateral superior and middle frontal gyri, bilateral frontal polar regions, and precuneus gyrus (92).

At the neurochemical level of analysis, a number of neurotransmitters have been linked to $\mathrm{EF}$ processes. A comprehensive review (93) summarized the role of four neurotransmitter systems in EF. Dopamine (DA) was reported to influence cool EF constructs (set shifting, response inhibition) and to moderate hot EF reward processes. Norepinephrine (NA) circuits were associated with a number of EF cognitive processes (including response inhibition and set shifting likely 
TABLE 2 | The definition and assessment measures of discrete EF domains.

EF domain

Set shifting/concept formation

Set shifting or concept formation is defined as the capacity to shift between mental processes to form new concepts and identify the conceptual relationships shared by stimuli $(12,50)$. Other commonly used terminology for set shifting includes concept formation and cognitive or mental flexibility (25). Theorized mechanisms for set shifting have included switching between mental processes. It has been argued, however, that set switching (51) represents a distinctly different EF component that needs to be differentiated from set shifting.
Neuropsychological and experimental task measures

Wisconsin Card Sorting Test (WCST) (52)

Intra/Extra Dimensional Shift (IED) - CANTAB (53)

Sorting test-D-KEFS (50)

Dimensional Change Card Sort test (DCCS) (54)

DCCS-NIH Cognition ToolBox (55)

Flexible Item Selection Task (FIST) (56).

Set Shifting test-CogState (https://www.cogstate.com/

Rule Shift Cards test-BADS (57)

Temporal Judgement test-BADS (57)

Mental flexibility/set switching

Set switching has been defined as the capacity to switch between mental processes (multiple tasks, operations, or mental sets) in response to changing demands $(51,58)$. It is distinct from set shifting, where the focus is on identifying novel relationships.

Fluency

Fluency is defined as the capacity to generate verbal and non-verbal stimuli including ideas, designs (50), and words (60). Verbal fluency is a frequently studied measure of executive functioning (34) and is distinguished into phonemic (generativity for unrelated words) and semantic fluency (generativity for semantically related words or categories) (61). There is some debate as to whether phonemic and semantic fluency represent EF $(36,60)$ or language processes (62). However, a number of studies supported by neuroimaging findings (34) suggest that verbal fluency is reliant on core EF processes (63, 64).

Planning

Planning is defined as the capacity to execute a sequence of actions so that a desired goal is achieved (36).

Response inhibition

Response inhibition primarily refers to the ability to inhibit a previously learned or prepotent response (12). Two additional components contribute to inhibition: resistance to distractor interference and resistance to proactive interference (68). Resistance to distractor interference refers to the ability to process a target stimulus while ignoring irrelevant information presented at the same time, while resistance to proactive interference refers to the ability to efficiently process distractors from recently activated memory stimuli. Some research classifies resistance to proactive interference as a working memory process.

Hot EF

Top-down processes activated in situations with motivational and emotional significance (76).
Trails Making Test (Trails B) (59).

Trails Making Test-D-KEFS (50)

Controlled Oral Word Association Test (COWAT) (65)

Verbal Fluency test-D-KEFS (50)

Design Fluency test-D-KEFS (50).

20 Questions Test-D-KEFS (50)

Word Context test-D-KEFS (50)

Proverb test-D-KEFS (50)

Tower of Hanoi (66)

Tower of London (67)

One Touch Stockings (OTS) - CANTAB (53)

Stockings of Cambridge (SOC) - CANTAB (53)

Action Programme Planning test-BADS (57)

Key Search test-BADS (57)

Zoo Map test-BADS (57)

Modified Six Elements test-BADS (57)

Stroop test (69)

Color-Word Interference Test-D-KEFS (50)

Go/no-go task (70)

Hayling test (71)

Eriksen flanker task (72).

Stop Signal Task-CANTAB (53)

Flanker Inhibitory Control and Attention test-NIH

Cognition ToolBox (55)

Go-No Go Test-CogState (https://www.cogstate.com/)

Letter sequencing task (73)

Digits Backwards - Wechsler Memory Scale (74)

Spatial Working Memory (SWM) - CANTAB (53).

Spatial Span (SSP) - CANTAB (53)

List Sorting Working Memory Test-NIH Cognition ToolBox (55)

n-back task (75)

One Back test-CogState (https://www.cogstate.com/)

Two Back test-CogState (https://www.cogstate.com/)

Affective Go/No-go (AGN) - CANTAB (53)

Cambridge Gambling Task (CGT) - CANTAB (53)

Information Sampling Task (IST) - CANTAB (53)

lowa Gambling test (77) 
TABLE 2 | Continued

EF domain

Emotional/personality change, motivational change, behavioral change, cognitive change

Global executive composite

Behavioral Regulation Index-initiate, organization of materials, plan/organize, task monitor, working

memory

Metacognition Index-emotional control, inhibit, self-monitor, shift

Self-management in time, self-organization/problem solving, self-restraint, self-motivation, self-regulation of emotion

BADS, Behavioural Assessment of the Dysexecutive Syndrome; CANTAB, Cambridge Neuropsychological Test Automated Battery; D-KEFS, Delis-Kaplan Executive Function System.

due to influence of NA on arousal and attentional systems. Serotonin (5-hydroxytrypatamine [5-HT]) modulated response inhibition, through its action in the orbitofrontal cortex. Finally, the cholinergic system mediated set shifting and was proposed to also interact with a number of other neural circuits for a more complex integration of EF processes.

The role of $\gamma$-aminobutyric acid (GABA) is increasingly linked with mediating processes associated with neural circuitry in the prefrontal cortex. GABA is the primary inhibitory neurotransmitter in the mature brain, working with excitatory glutamate to create an excitation/inhibition (E/I) balance thought to reflect the activity of the cortex. More excitation is theorized to represent greater activity, while greater inhibition suggests decreased cortical activity (94). Increased GABA (compared to glutamate) within the lateral PFC has been associated with better ability to select between competing tasks (95). Improved working memory performance under increased memory load was associated with higher GABA concentration in the dorsolateral PFC. A recent study (pre-print) (47) attributed a key role to GABAergic genetic contributions to the common EF factor (45), using a large sample in a genome-wide association study (GWAS). This study highlighted the role of the excitatory/inhibitory balance in EF, especially the role of GABA-mediated inhibition.

The models described above reflect the divergent approaches taken in the study of EF in normative literature. In ASD, however, focus has been primarily on comparing diagnostic groups with autism and other cohorts on performance on discrete EF constructs. The executive dysfunction hypothesis discussed below sums a large part of empirical research of EF in ASD. It may reflect efforts to identify discriminating profiles between different groups. Novel approaches to the study of EF in ASD have focused on brain connectivity and neurotransmitter imbalance with limited evaluation of other EF models.

\section{EXECUTIVE FUNCTION AND AUTISM SPECTRUM DISORDER}

\section{Executive Dysfunction Hypothesis}

Early studies of EF in ASD were summarized in a review by Pennington and Ozonoff (10). Executive dysfunction was proposed as a model for understanding behavioral problems in ASD, including impaired theory of mind (ToM). Their review of research studies across neurodevelopmental disorders suggested that discrete EFs (set shifting, response inhibition, and working memory) might be appropriate cognitive markers for differentiating between ASD and ADHD.

Empirical findings on EF deficits in ASD were subsequently formalized in the executive dysfunction hypothesis (25) proposed in an effort to review and integrate the extant literature of EF in ASD. The review focused on four EFs: planning, mental flexibility, inhibition, and self-monitoring, assumed to represent the core EF domains. The executive dysfunction hypothesis suggested impairment on distinct EF domains, supporting a fractionated model of EF. In addition to identifying impairment in EFs, the review also highlighted considerable variability in EF performance between studies and within cohorts.

Since the introduction of the executive dysfunction hypothesis, there has been a proliferation of studies investigating cool EFs in ASD; these have been synthesized in a number of meta-analyses. Findings in the extant literature of executive dysfunction and heterogeneity in EF performance complement the observations made by Hill (25) and Pennington (10).

A meta-analysis on cognitive flexibility (96) indicated life span impairment in ASD. The study adopted a broad definition of cognitive flexibility and combined research on set shifting, set switching, and inhibitory control. A meta-analysis in children and youth investigating the components of response inhibition, prepotent response inhibition and interference control, identified age related differences (68). Impairment in prepotent response inhibition attenuated with increasing age, whereas difficulties in interference control persisted across the life span. An investigation of working memory (97) in children and young adolescents revealed impairment across both verbal and spatial working memory. There were no age-related differences; however, a larger effect size was observed for spatial compared to verbal working memory, suggesting greater difficulties in the spatial domain for youth with ASD. Planning is considered a key EF in adaptive behavior, and a meta-analysis reported impairment in planning for individuals with ASD (98). Planning difficulties were independent of moderator influences of age, intellectual functioning, and assessment type. The meta-analyses described above confirm impairment in discrete EFs; however, it remains uncertain whether these are underpinned by a common mechanism or whether discrete EFs are differentially impaired in ASD. 
Two recent meta-analyses $(22,23)$ investigated cool EFs in ASD across multiple EF domains and thus address this question. Broad impairment in EF was observed both in children and youth (22) and across the life span (23). In the (22) metaanalysis, impairment in response inhibition and planning was less prominent compared to deficits in flexibility (set switching and set shifting), generativity/fluency, and working memory. Impairment across all of the above domains was identified in the (23) meta-analysis. Both studies suggest that an underlying common pathway may influence EF processes in ASD.

The meta-analyses described above also identified substantial heterogeneity in EF performance, despite consideration of a number of moderator variables. Hot EFs may be contributing to the unexplained heterogeneity, particularly in the view that they are independent of cool EF processes $(86,99)$. Comparable to most research of cool EFs in ASD, the study of hot EFs principally adopted the fractionated approach investigating discrete domains. Impairment has been observed in tasks associated with affective decision making and delay discounting $(85,100)$. Given the limited studies completed to date, it is unclear whether hot EFs could alone explain the heterogeneity observed in EF performance in ASD.

\section{Atypical Brain Connectivity}

Throughout the ASD literature, there have been consistent findings of atypical functional connectivity, though this has varied between over-connectivity and under-connectivity (101). The regions impacted in ASD include areas encompassed by the default, salience, and executive control networks (102) and in cortical-subcortical circuitry (103). When connectivity is investigated for distinct EFs, there are reported differences in the circuitry associated with working memory (104) and response inhibition (105), with atypicalities reported to persist across the life span (106).

\section{The Excitation/Inhibition Hypothesis (E/I)}

The E/I model (107) examines observed behavior in ASD at the neural level. The E/I model focuses on the action of glutamate and GABA and the balance between the two. The model suggests that an imbalance between neural excitation (driven by glutamate) and neural inhibition (driven by GABA) in brain circuits contributes to ASD symptomatology (108) and associated impairment in perceptual, motor, and cognitive systems $(107,109)$. The links between ASD, EF, and the E/I hypothesis have not been extensively investigated. The observed reductions in GABA concentration and GABA receptors in the frontal lobes (110) suggest a likely influence of GABA on frontal lobe processes, including EF. For example, greater concentrations of GABA in the frontal lobe have previously been associated with superior cognitive performance (111). It is theorized that reductions in frontal GABA may be contributing to the broad EF difficulties in ASD. Furthering this hypothesis is tentative support that GABA may relate to response inhibition processes (112). Evidence that the E/I imbalance can be shifted with pharmacological interventions, and that this shift is accompanied by a normalization of functional connectivity patterns in the frontal regions (113), suggests a potential intervention strategy for ASD that may lead to improvements in cognitive processes, including EF.

\section{Moderating Influences on EF in ASD}

Moderator variables and other mediating factors (e.g. measurement of EF construct) may contribute to the observed variability of EF findings in ASD. A number of these factors are discussed below.

\section{Measurement of EF}

The validity and reliability of EF measures may significantly moderate observed performance. Validity refers to the extent that the EF assessment tool accurately taps the theorized EF construct $(36,114)$. Reliability refers to the consistency of the EF assessments to measure the EF construct (36). Research in EF has been criticized for lacking valid and reliable measures. The main criticism relates to the lack of task purity in the tools utilized to measure EF $(10,64)$. It has been demonstrated that EF assessment tools likely measure multiple EF and non-EF processes, thus challenging their efficacy to assess distinct EFs.

Measurement of EF has traditionally focused on neuropsychological assessments sensitive to frontal lobe damage $(50,115)$. Assessment tools, however, including classic measures such as the Wisconsin Card Sorting Test (WCST) (115) are not pure measures of the underlying EF, e.g., set shifting (52). Experimental tasks have also been utilized as likely purer measures of discrete EFs (12). More recently, development of behavioral rating scales $(37,116)$ aimed to provide more ecologically valid assessments of EF $(37,117$, 118) focusing on executive regulation of everyday behaviors. Studies in ASD demonstrated a significantly larger effect size for behavioral rating scales compared to neuropsychological and experimental measures (23). These findings suggest that behavioral measures may better capture EF processes and are more ecologically valid (118).

\section{Developmental Trajectory of EF}

An overview of the developmental trajectory of cool EFs in neurotypical development and in ASD is presented in Figure 1. In typical development, maturation of EFs begins in infancy and continues throughout childhood and adolescence and into early adulthood $(119,120)$. The rate of improvement for individual components, with the exception of fluency, begins to taper at about age 12 (119), with most EFs reaching their peak in late adolescence/in the early 20s (120).

In ASD, there is evidence of executive dysfunction across development for discrete EF domains (e.g. working memory, set shifting/switching, fluency) $(22,68,121)$ with some support of improvements in EF ability over time (122). Developmental research of hot EFs in ASD is limited. Recent research found no significant age-related changes in ASD in the neurotypical comparison group (100). This contrasts with other research in neurotypical development that suggests a variable developmental trajectory $(76,99)$.

The variability in peak developmental periods for distinct EFs may be contributing to some of the heterogeneity observed in EF performance in ASD. The use of mixed age groups in ASD research mask these differences and could contribute to variability observed between studies. 


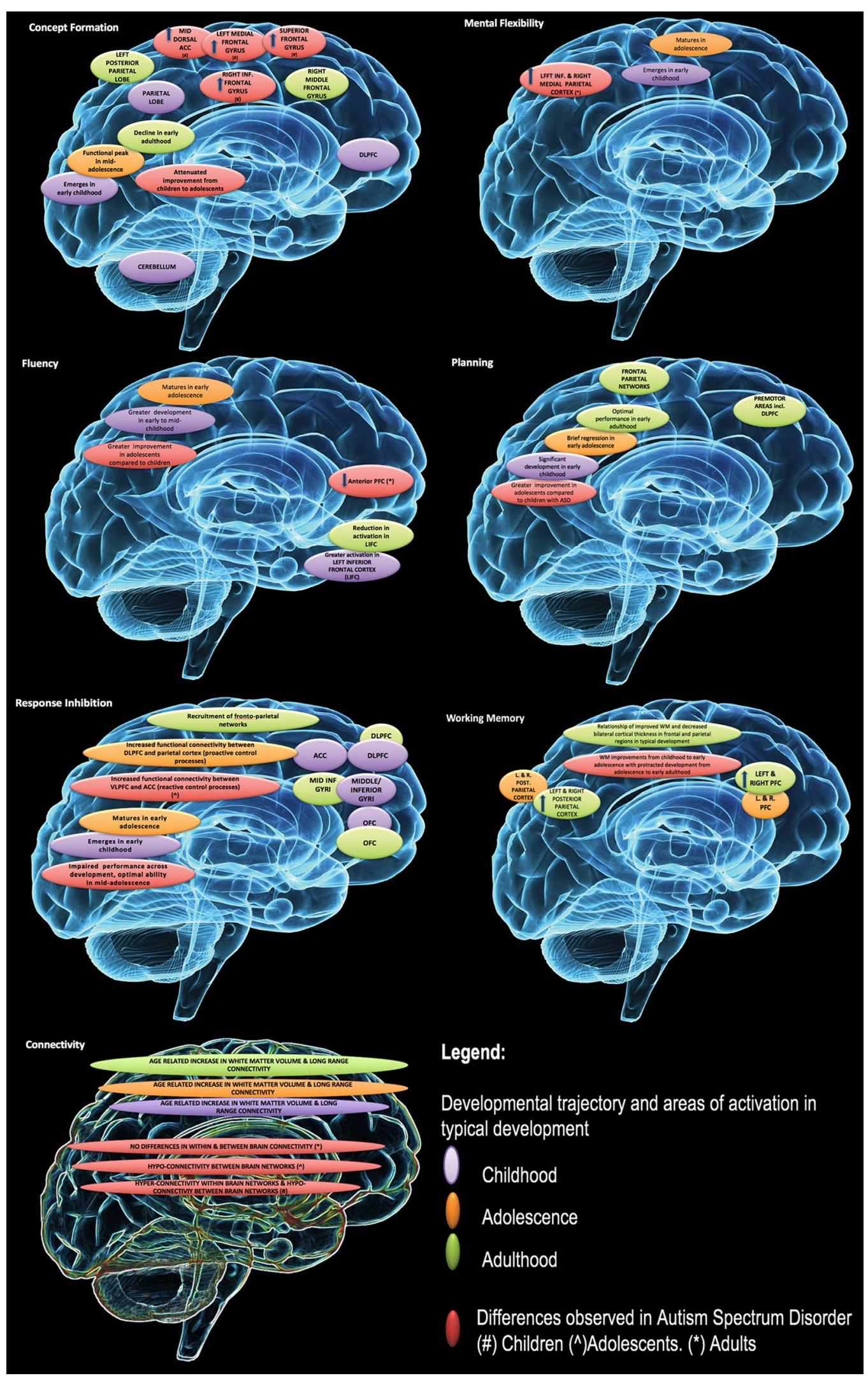

FIGURE 1 | Developmental changes in executive function and associated impairment in autism spectrum disorders (ASD). Reproduced with permission from (23). 


\section{Moderator Variables of EF General Intellectual Functioning}

Early research on EF developed partly based on observations that higher cognitive processes (e.g. planning, concept formation) may be impaired despite intact intellectual functioning. Despite this general observation, there is some empirical support that intellectual ability may moderate performance on neuropsychological assessments of EF (123). This is pertinent in the study of ASD, where differences between specific indices of intelligence (verbal, perceptual, and full-scale intelligence scales) have been reported for the clinical subgroups of autistic disorder and Asperger's syndrome (124).

\section{Sample Characteristics and Task Characteristics}

Each study sets its own criteria to define eligibility and to enroll ASD participants, creating a lack of consistency between studies. These differences include ASD diagnosis (as per earlier Diagnostic and Statistical Manual of Mental Disorders [DSM] classifications), choice of comparison groups, age, and criteria matching the ASD cohort to the comparison group. The diagnostic criteria for ASD have broadened significantly since the first inclusion of autism in the DSM-III (125). In DSM-5 (1), discrete diagnostic categories (autistic disorder, Asperger's syndrome) have been merged into a single spectrum, facilitating uniformity in the diagnostic selection criteria (but likely introducing greater heterogeneity). Prior to the introduction of the DSM-5, a number of studies were comprised of mixed diagnostic classifications (126-129), while some studies included the informal classification of high functioning autism (HFA) (130). HFA defined ASD cohorts with no intellectual disability (IQ greater than 70). However, inclusion criteria on level of intellectual functioning ranged between studies from borderline (131), low average (129), to average (132). This could have contributed to greater variability in intellectual and executive functioning and may in part explain differences between studies.

Most studies have utilized standardized diagnostic assessments of ASD (Autism Diagnostic Observation Schedule [ADOS], Autism Diagnostic Interview [ADI]) and DSM-based diagnostic criteria. Some studies may utilize screening assessments $(132,133)$ or classification criteria not drawn from the DSM (134). These factors may also contribute to the variability in EF performance.

Selection of comparison control groups also varies between studies. Although most studies include neurotypical comparison groups, there have also been comparisons conducted with nonaffected siblings $(135,136)$ or clinical groups only (137-139).

The type of assessment, whether it is a psychometric test, an experimental task, or a behavioral rating scale, is an important moderating factor in the discussion of EF. It has been suggested that behavioral rating scales capture different underlying mechanisms (140) compared to performance-based tasks and therefore should not be utilized as substitute measures of EF performance. In particular, self-ratings on behavior may reflect individual's motivation for goal setting, achieving personal goals, and their personal expectations in relation to these goals (140). By comparison, neuropsychological assessments and experimental tasks are performance-based measures that measure EF within the designed parameters of the task. Research in ADHD (141) and ASD (20) lends some support that different cognitive mechanisms may underpin these measures. For example, low correlations were reported between performance measures and a behavioral rating scale of EF (142).

Administration format (traditional versus computerized presentations of test material) may also moderate EF performance. There is evidence that individuals with ASD perform better on computerized administration in comparison to traditional administration of EF tests $(118,143)$, although this is not unequivocal (144). Further, the presentation format of the test stimulus (verbal versus visual stimuli) and participant response format (motor versus verbal response) may be important moderators. This is particularly relevant to ASD research, as there is some support for superior performance in individuals with ASD in visuoperceptual tasks requiring attention to detail (145).

\section{Sex Differences}

ASD is a neurodevelopmental condition that occurs more in males, currently with about three males diagnosed to every one female (146). A number of theories have been proposed to explain this difference. These are based on genetic and/ or neurobiological differences between males and females as described, for example, in the imprinted-X liability model (147), the male brain theory (148), and the female protective effect theory $(149,150)$. There is growing interest in identifying the characteristics that might differentiate male and female individuals with ASD, including EF performance. However, comparisons of males and females with ASD on neuropsychological assessments and self-/informant appraisals of EF have been limited. Some research findings (151-153) suggest differences between males and females with ASD on EF performance, while others report no differences $(154,155)$. One potential confounding factor is that not all studies included sex-matched neurotypical control groups. Sex differences in cognitive performance observed in neurotypical populations may also be present between females and males with ASD. These, however, will not be identified in ASD cohorts without comparisons to sex-matched neurotypical controls.

\section{Co-Morbid Conditions and Affective States}

The presence of co-morbid ADHD may influence EF performance in ASD, and this was particularly evident in inhibition (156). Other co-morbid conditions (e.g. depression, anxiety) have a high prevalence in individuals with ASD (157) and may have a moderating role on EF. In particular, the influence of anxiety (158) and stress (159) on EF has been well documented. Overall, research to date suggests a moderating effect of anxiety on cognitive function in non-clinical samples of highly anxious individuals (160-163). In ASD, anxiety negatively correlated with test performance on neuropsychological assessments of concept formation (18). Anxiety was also shown to correlate with impaired performance on neuropsychological measures of inhibition, mental flexibility, and shifting (164). The links 
between affective states and EF highlight the importance of investigating their role in ASD research.

\section{Heterogeneity of EF}

The preceding discussion highlighted that observed executive impairment in ASD is characterized by heterogeneity with a range of contributing of factors. A research framework that can utilize EF as a marker and facilitate classification of ASD into distinct subtypes could contribute to diagnostic and intervention strategies for this group. Using cognitive and neuroimaging measures, three ASD subtypes were identified in a recent study based in part on performance on response inhibition tasks (165). A second study (166) showed that performance measures of cognitive flexibility distinguish between children with and without ASD. Interestingly, however, extension of the above study to brain connectivity circuits of cognitive flexibility did not identify subtypes at the neural level (167). The authors suggested that a dimensional approach might be more appropriate for some cognitive processes. The $\mathrm{RDoC}$ framework (29) incorporates a dimensional approach and can evaluate EF across cognitive and neural measures. We discuss below the efficacy of EF as an endophenotype for ASD and propose that the RDoC framework can advance research of EF in ASD.

\section{EXECUTIVE FUNCTION AS A COGNITIVE INTERMEDIATE PHENOTYPE}

Endophenotypes, or intermediate phenotypes (168), are characteristics that present vulnerabilities in a particular population, linking genes, brain processes, and observed behavior. Endophenotypes may encompass neurocognitive functions (136, 169), making EF a likely candidate. Criteria that must be satisfied for considering a marker as an endophenotype include: the marker must be associated with the illness/disorder in the population; it must be heritable; and it must present at higher rates within affected families than the general population (170).

The wealth of empirical findings linking EF with the broader ASD phenotype (in particular, the diagnostic clusters as defined in the DSM-5) support its potential as an endophenotype. Early reviews of the literature $(171,172)$ and empirical studies reported a correlation between neuropsychological (129, 173, 174) and behavioral measures (175) of executive impairment with severity of repetitive behaviors. This relationship was reported for specific EF domains, such as cognitive flexibility, response inhibition, and working memory. Another study suggested that EF deficits were specific to repetitive but not restricted behavior patterns (15). These findings led to theories that linked restricted and repetitive behavior symptoms to EF, suggesting that EF constructs can differentiate within behavioral clusters in ASD. A number of studies show that EF influences ToM performance in $\operatorname{ASD}(17,176)$ and may influence the social communication cluster. The ToM model (5) was one of the prominent cognitive explanations for impaired social cognition in ASD. It proposed that impaired ability to attribute mental states to self and others contributes to a range of deficits including those observed in the social communication cluster (177). Recent research also indicated that ToM may predict disability (178). Support of a putative link between EF and ToM includes findings that reduced working memory moderated social communication skills (179). In summary, there is evidence that EF influences both diagnostic clusters of ASD (1) and would be a valuable endophenotype for targeted interventions.

EF has measurable behavioral outcomes $(37,142)$ and is linked to genetic (168) and neurobiological (180) processes. For example, functional imaging studies have demonstrated that neuropsychological assessments of EF are linked with activation of brain areas including frontoparietal (168) and frontal cortical areas (52). Further, genetic influences account for about half of the variability in EF performance $(45,168)$. The neural substrates of GABA and glutamate present a neural link for the EF (common factor) which has a genetic basis but may be measured with cognitive tasks (47). Lastly, there is empirical support that EF difficulties in relatives of probands with ASD are at a higher rate than the general population (181).

In summary, research on EF indicates that it satisfies the definition of endophenotypes and supports its role as an endophenotype for ASD.

\section{A RESEARCH FRAMEWORK AND FUTURE RESEARCH DIRECTIONS}

We suggest that a model of EF in ASD that bridges the pathway from genetics to neural circuitry and to the observed EF phenotype may better capture the heterogeneity of EF in ASD. The unity and diversity model $(12,45,46)$ provides a link for an integrated research framework for EF. The common EF factor could contribute to quantifying heterogeneity in EF performance in ASD. Complementing the above, investigation of core cool EFs (set shifting and working memory), hot EFs/behavioral regulation, and affective states in a single research framework can further advance the study of EF in ASD.

The RDoC framework (29) provides research guidelines that may resolve a number of the limitations observed in ASD research. The $\mathrm{RDoC}$ approach advocates a focus on a dimensional research framework. It is guided by research across "systems"-based domains that are evaluated by different levels of measurement (extending from the molecular/genetic level to the observed behavioral phenotype) (182).

The guiding principles of the RDoC framework (183) focus on: a dimensional systems approach, behavior-brain relationships, and multiple levels of analysis (molecular, circuit behavior, symptom). These principles align with the study of EF and ASD, creating a framework to guide this complex research area. Further, the RDoC framework can be adapted to reflect key characteristics of neurodevelopment (developmental trajectories/ sensitive periods) $(183,184)$ and can be particularly relevant to the study of neurodevelopmental conditions, including ASD.

The RDoC framework presently consists of six systems domains: negative valence systems, positive valence systems, cognitive systems, social processes, arousal and regulatory systems, and sensorimotor systems. Each system is characterized 
by different constructs that are evaluated across distinct units of analysis (or measurement): genes, molecules, cells, circuits, physiology, behavior, self-report, and paradigms. Research of EF in ASD brings together a number of these systems and specifically the "positive valence systems," "negative valence systems," and "cognitive systems."

The positive valence systems are responsible for responses to positive motivational situations or contexts, such as reward seeking. The negative valence systems are responsible for responses to aversive situations or context, such as fear, anxiety, and loss, and the cognitive systems domain is responsible for cognitive processes.

The positive valence systems domain presents a framework for integrating the relationship between hot EFs and behavioral regulation. Complementing these, the negative valence systems domain captures the contribution of anxiety in ASD (157) and its moderating role in EF outcomes (158). Within the cognitive systems domain, the constructs of cognitive control and working memory reflect the EF factors of the unity and diversity model (12). These can evaluate the contribution of cool EFs in ASD. Investigated together, these three systems would provide researchers with a common language facilitated by a consensus on the specific components under each unit of analysis. Furthermore, such an integrated approach would provide greater opportunity to identify subtype profiles within ASD. Targeted intervention strategies can then be tailored to each profile with primary focus on the domains of the cognitive, positive, and negative valence systems. A summary of the proposed integrated framework is presented in Figure 2.

\section{CONCLUSION}

EF is an important factor in the study of ASD and with great potential as an endophenotype. Despite the plethora of theoretical models, there is conceptual confusion in EF research that would benefit from a unified research methodology. The findings of broad EF impairment in ASD are an important step, as they unify much of the research on cool EFs and highlight that differences are likely guided by genetic variability in EF processes. The application of the RDoC framework has potential to improve our understanding of

\section{REFERENCES}

1. American Psychiatric Association. Diagnostic and statistical manual of mental disorders. Washington, DC: American Psychiatric Association (2013). doi: 10.1176/appi.books.9780890425596

2. Wagner RE, Zhang Y, Gray T, Abbacchi A, Cormier D, Todorov A, et al. Autism-related variation in reciprocal social behavior: a longitudinal study. Child Dev (2018) 0(0):441-51. doi: 10.1111/cdev.13170

3. Papagiannopoulou EA, Chitty KM, Hermens DF, Hickie IB, Lagopoulos J. A systematic review and meta-analysis of eye-tracking studies in children with autism spectrum disorders. Soc Neurosci (2014) 9(6):610-32. doi: 10.1080/17470919.2014.934966

4. Caruana N, Stieglitz Ham H, Brock J, Woolgar A, Kloth N, Palermo R, et al. Joint attention difficulties in autistic adults: an interactive eye-tracking study. Autism (2017) 22(4):502-12. doi: 10.1177/1362361316676204

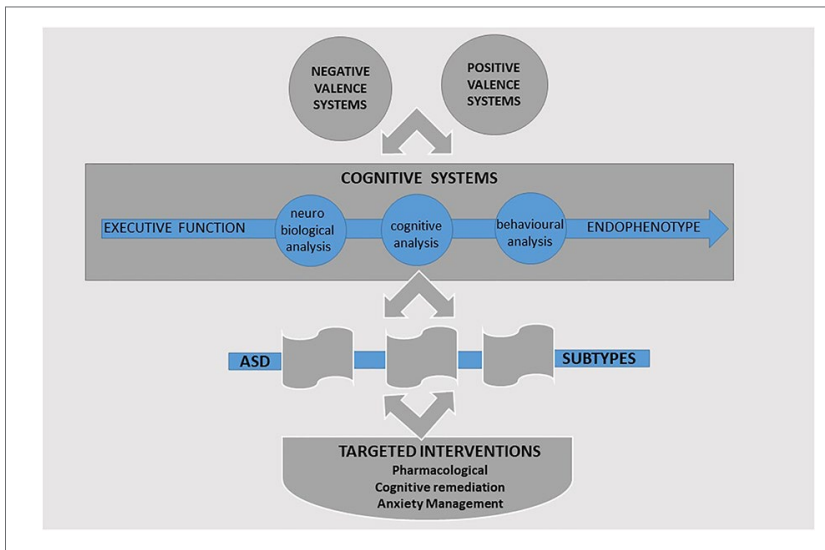

FIGURE 2 | A research framework for the study of executive function (EF) in ASD.

EF in ASD and elucidate the mechanisms responsible. RDoC presents a framework to integrate research obtained from diverse measures (neuropsychological tests, experimental tasks, behavioral ratings) to characterize the relevant circuitry and investigate additional factors (e.g. hot EFs) and moderators (e.g. anxiety). Taken together, the RDoC approach presents new opportunities for profiling ASD subtypes and for targeted assessments and interventions.

\section{AUTHOR CONTRIBUTIONS}

ED and AG contributed to the conception and planning of the review. ED conducted the literature search and provided the initial draft. ED, MD, and AG wrote sections of the manuscript. All authors contributed to manuscript revision, read and approved the submitted version.

\section{FUNDING}

This work was supported by an Australian Research Council Linkage Grant (LP110200562) to AG and a NHMRC scholarship (GNT1056587) to ED.

5. Baron-Cohen S, Leslie AM, Frith U. Does the autistic child have a "theory of mind"? Cognition (1985) 21(1):37-46. doi: 10.1016/0010-0277(85) 90022-8

6. South M, Ozonoff S, McMahon WM. Repetitive behavior profiles in Asperger syndrome and high-functioning autism. J Autism Dev Disord (2005) 35(2):145-58. doi: 10.1007/s10803-004-1992-8

7. Happé F, Frith U. The weak coherence account: detail-focused cognitive style in autism spectrum disorders. J Autism Dev Disord (2006) 36(1):5-25. doi: 10.1007/s10803-005-0039-0

8. Lever AG, Geurts HM. Age-related differences in cognition across the adult lifespan in autism spectrum disorder. Autism Res (2016) 9(6):666-76. doi: 10.1002/aur.1545

9. Olde Dubbelink LME, Geurts HM. Planning skills in autism spectrum disorder across the lifespan: a meta-analysis and meta-regression. J Autism Dev Disord (2017) 47(4):1148-65. doi: 10.1007/s10803-016-3013-0 
10. Pennington BF, Ozonoff S. Executive functions and developmental psychopathology. J Child Psychol Psychiatry (1996) 37(1):51-87. doi: 10.1111/j.1469-7610.1996.tb01380.x

11. Hill EL. Evaluating the theory of executive dysfunction in autism. Dev Rev (2004a) 24(2):189-233. doi: 10.1016/j.dr.2004.01.001

12. Miyake A, Friedman NP, Emerson MJ, Witzki AH, Howerter A, Miyake A, et al. The unity and diversity of executive functions and their contributions to complex "frontal lobe" tasks: a latent variable analysis. Cognit Psychol (2000) 41(1):49-100. doi: 10.1006/cogp.1999.0734

13. Ozonoff S, Jensen J. Specific executive function profiles in three neurodevelopmental disorders. J Autism Dev Disord (1999) 29(2):171-7. doi: 10.1023/A:1023052913110

14. South M, Ozonoff S, McMahon WM. The relationship between executive functioning, central coherence, and repetitive behaviors in the highfunctioning autism spectrum. Autism (2007) 11(5):437-51. doi: $10.1177 / 1362361307079606$

15. Boyd BA, McBee M, Holtzclaw T, Baranek GT, Bodfish JW. Relationships among repetitive behaviors, sensory features, and executive functions in high functioning autism. Res Autism Spectr Disord (2009) 3(4):959-66. doi: 10.1016/j.rasd.2009.05.003

16. Jones CRG, Simonoff E, Baird G, Pickles A, Marsden AJS, Tregay J, et al. The association between theory of mind, executive function, and the symptoms of autism spectrum disorder. Autism Res (2018) 11(1):95-109. doi: 10.1002/aur.1873

17. Kouklari E-C, Tsermentseli S, Auyeung B. Executive function predicts theory of mind but not social verbal communication in school-aged children with autism spectrum disorder. Res Dev Disabilities (2018a) 76:12-24. doi: 10.1016/j.ridd.2018.02.015

18. Zimmerman D, Ownsworth T, O’Donovan A, Roberts J, Gullo MJ. Associations between executive functions and mental health outcomes for adults with autism spectrum disorder. Psychiatry Res (2017) 253(Supplement C):360-3. doi: 10.1016/j.psychres.2017.04.023

19. Pugliese CE, Anthony LG, Strang JF, Dudley K, Wallace GL, Naiman DQ, et al. Longitudinal examination of adaptive behavior in autism spectrum disorders: influence of executive function. J Autism Dev Disord (2016) 46(2):467-77. doi: 10.1007/s10803-015-2584-5

20. Demetriou EA, Song CY, Park SH, Pepper KL, Naismith SL, Hermens DF, et al. Autism, early psychosis, and social anxiety disorder: a transdiagnostic examination of executive function cognitive circuitry and contribution to disability. Transl Psychiatry (2018b) 8(1):200. doi: 10.1038/s41398-018$0193-8$

21. Wallace GL, Budgett J, Charlton RA. Aging and autism spectrum disorder: evidence from the broad autism phenotype. Autism Res (2016a) 9(12):1294303. doi: 10.1002 /aur.1620

22. Lai CLE, Lau Z, Lui SSY, Lok E, Tam V, Chan Q, et al. Meta-analysis of neuropsychological measures of executive functioning in children and adolescents with high-functioning autism spectrum disorder. Autism Res (2017a) 10(5):911-39. doi: 10.1002/aur.1723

23. Demetriou EA, Lampit A, Quintana DS, Naismith SL, Song YJC, Pye JE, et al. Autism spectrum disorders: a meta-analysis of executive function. Mol Psychiatry (2018) 23(5):1198-204. doi: 10.1038/mp.2017.75

24. Geurts H, Sinzig J, Booth R, HappÉ F. Neuropsychological heterogeneity in executive functioning in autism spectrum disorders. Int $J$ Dev Disabilities (2014a) 60(3):155-62. doi: 10.1179/2047387714Y.0000000047

25. Hill EL. Executive dysfunction in autism. Trends Cogni Sci (2004b) 8(1):2632. doi: $10.1016 /$ j.tics.2003.11.003

26. Luria AR. Higher cortical functions in man. Oxford England: Basic Books (1966).

27. Baddeley A. Exploring the central executive. Q J Exp Psychol Sect A (1996) 49(1):5-28. doi: 10.1080/027249896392784

28. Stuss DT. Functions of the frontal lobes: relation to executive functions. J Int Neuropsychol Soc (2011) 17(5):759-65. doi: 10.1017/S1355617711000695

29. Insel TR. The NIMH Research Domain Criteria (RDoC) Project: precision medicine for psychiatry. Am J Psychiatry (2014) 171(4):395-7. doi: 10.1176/ appi.ajp.2014.14020138

30. Pribram MI, Snyder CRR. Attention and cognitive control. In: Solso R, editor. Information processing and cognition: the Loyola symposium. Hillsdale, NJ: Lawrence Erlbaum (1975). p. 55-85.

31. Harlow J. Passage of an iron bar through the head. Boston Med Surg J (1848) 39:389-93. doi: 10.1056/NEJM184812130392001
32. Stuss DT, Benson DF. The frontal lobes. New York: Raven (1986).

33. Szczepanski SM, Knight RT. Insights into human behavior from lesions to the prefrontal cortex. Neuron (2014) 83(5):1002-18. doi: 10.1016/j.neuron.2014.08.011

34. Alvarez JA, Emory E. Executive function and the frontal lobes: a metaanalytic review. Neuropsychol Rev (2006) 16(1):17-42. doi: 10.1007/ s11065-006-9002-x

35. Otero TM, Barker LA. The frontal lobes and executive functioning. In: Goldstein S, Naglieri JA, editors. Handbook of executive functioning. New York, NY: Springer New York (2014). p. 29-44. doi: 10.1007/978-1-4614-8106-5_3

36. Lezak MD, Howieson DB, Bigler ED, Tranel D. Neuropsychological assessment. 5th edition. New York, NY US: Oxford University Press (2012).

37. Barkley RA. The assessment of executive functioning using the Barkley Deficits in Executive Functioning Scales. In: Goldstein S, Naglieri JA, editors. Handbook of executive functioning. Springer New York (2014). p. 245-63. doi: 10.1007/978-1-4614-8106-5_15

38. Baggetta P, Alexander P. Conceptualization and operationalization of executive function. Mind Brain Educ (2016) 10(1):10-33. doi: 10.1111/mbe.12100

39. Hunter S, Sparrow E. Models of executive functioning. Executive function and dysfunction. Cambridge: Cambridge University Press (2012). doi: 10.1017/ CBO9780511977954

40. Baddeley A. Working memory: theories, models, and controversies. Annu Rev Psychol (2012) 63(1):1-29. doi: 10.1146/annurev-psych-120710-100422

41. Gathercole S, Alloway T. Working memory and learning: a practical guide for teachers. Sage Publication: London (2008).

42. Posner MI. Orienting of attention. Q J Exp Psychol (1980) 32(1):3-25. doi: $10.1080 / 00335558008248231$

43. Shallice T. Fractionation of the supervisory system. In: Stuss D, Knight R, editors. Principles of frontal lobe function. New York: Oxford University Press (2002). p. 261-77. doi: 10.1093/acprof:oso/9780195134971.003.0017

44. Hughes C, Russell J, Robbins TW.Evidence for executive dysfunction in autism. Neuropsychologia (1994) 32(4):477-92. doi: 10.1016/0028-3932(94)90092-2

45. Friedman NP, Miyake A, Young SE, DeFries JC, Corley RP, Hewitt JK. Individual differences in executive functions are almost entirely genetic in origin. J Exp Psychol (2008) 137(2):201-25. doi: 10.1037/0096-3445.137.2.201

46. Friedman NP, Miyake A. Unity and diversity of executive functions: individual differences as a window on cognitive structure. Cortex (2017) 86:186-204. doi: 10.1016/j.cortex.2016.04.023

47. Hatoum AS, Mitchell EC, Morrison CL, Evans LM, Keller MC, Friedman NP. GWAS of over 427,000 individuals establishes GABAergic and synaptic molecular pathways as key for cognitive executive functions. bioRxiv (2019) 674515. doi: 10.1101/674515

48. Gioia G, Isquith PK, Guy SC, Kenworthy L. Behavior Rating Inventory Of Executive Function. Child Neuropsychol (2000) 6(3):235-8. doi: 10.1076/ chin.6.3.235.3152

49. Luria AR. Frontal lobe syndromes. In: Vinken P, Bruyn G, editors. Handbook of clinical neurology. vol. 2, North Holland, Amsterdam (1969). p. 725-57.

50. Delis DC, Kaplan E, Kramer JH. D-KEFS Executive Function System: examiners manual. San Antonio, TX: Psychological Corporation (2001). doi: 10.1037/t15082-000

51. Ravizza SM, Carter CS. Shifting set about task switching: behavioral and neural evidence for distinct forms of cognitive flexibility. Neuropsychologia (2008) 46(12):2924-35. doi: 10.1016/j.neuropsychologia.2008.06.006

52. Buchsbaum B, Greer R,S, Chang WL, Berman Karen XXXF. Meta-analysis of neuroimaging studies of the Wisconsin card-sorting task and component processes. Hum Brain Mapp (2005) 25(1):35-45. doi: 10.1002/hbm.20128

53. De Luca CR, Wood SJ, Anderson V, Buchanan J-A, Proffitt TM, Mahony K, et al. Normative data from the CANTAB. I: development of executive function over the lifespan. J Clin Exp Neuropsychol (2003) 25(2):242-54. doi: 10.1076/jcen.25.2.242.13639

54. Zelazo PD. The Dimensional Change Card Sort (DCCS): a method of assessing executive function in children. Nat Protoc (2006) 1:297. doi: 10.1038/nprot.2006.46

55. Akshoomoff N, Newman E, Thompson WK, McCabe C, Bloss CS, Chang L, et al. The NIH Toolbox Cognition Battery: results from a large normative developmental sample (PING). Neuropsychol (2014) 28(1):1-10. doi: 10.1037/neu0000001

56. Yerys BE, Wolff BC, Moody E, Pennington BF, Hepburn SL. Brief report: Impaired Flexible Item Selection Task (FIST) in school-age children with 
autism spectrum disorders. J Autism Dev Disord (2012) 42(9):2013-20. doi: 10.1007/s10803-012-1443-x

57. Wilson B, Evans J, Alderman N, Burgess P, Emslie H. Behavioural Assessment of the Dysexecutive Syndrome. In: Rabbit P, editor. Theory and methodology of frontal and executive function. East Sussex UK: Psychology Press (1997). p. $239-50$.

58. Arbuthnott K, Frank J. Trail Making Test, Part B as a measure of executive control: validation using a set-switching paradigm. J Clin Exp Neuropsychol (2000) 22(4):518-28. doi: 10.1076/1380-3395(200008)22:4;1-0;FT518

59. Reitan RM, Wolfson D. Trail Making Test: manual for administration and scoring. Tucson, AZ: Neuropsychological Press (1985).

60. Aita S, Boettcher A, Slagel B, Holcombe J, Espenan M, King M, et al. The relation between verbal fluency and executive functioning: an exploratory factor analysis (EFA) approach. Arch Clin Neuropsychol (2016) 31(6):656-6. doi: 10.1093/arclin/acw043.191

61. Costafreda SG, Fu CHY, Lee L, Everitt B, Brammer MJ, David Anthony S. A systematic review and quantitative appraisal of fMRI studies of verbal fluency: role of the left inferior frontal gyrus. Hum Brain Mapp (2006) 27(10):799-810. doi: 10.1002/hbm.20221

62. Whiteside DM, Kealey T, Semla M, Luu H, Rice L, Basso MR, et al. Verbal fluency: language or executive function measure? Appl Neuropsych-Adul (2016) 23(1):29-34. doi: 10.1080/23279095.2015.1004574

63. Piatt AL, Fields JA, Paolo AM, Tröster AI. Action (verb naming) fluency as an executive function measure: convergent and divergent evidence of validity. Neuropsychologia (1999) 37(13):1499-503. doi: 10.1016/ S0028-3932(99)00066-4

64. Snyder HR, Miyake A, Hankin BL. Advancing understanding of executive function impairments and psychopathology: bridging the gap between clinical and cognitive approaches. Front Psychol (2015) 6:328. doi: 10.3389/ fpsyg. 2015.00328

65. Ruff RM, Light RH, Parker SB, Levin HS. Benton Controlled Oral Word Association Test: reliability and updated norms. Arch Clin Neuropsychol (1996) 11(4):329-38. doi: 10.1093/arclin/11.4.329

66. Goel V, Grafman J. Are the frontal lobes implicated in "planning" functions? Interpreting data from the Tower of Hanoi. Neuropsychologia (1995) 33(5):623-42. doi: 10.1016/0028-3932(95)90866-P

67. Unterrainer JM, Rahm B, Kaller CP, Leonhart R, Quiske K, Hoppe-Seyler K, et al. Planning abilities and the Tower of London: is this task measuring a discrete cognitive function? J Clin Exp Neuropsychol (2004) 26(6):846-56. doi: 10.1080/13803390490509574

68. Geurts HM, Bergh SFWM, Ruzzano L. Prepotent response inhibition and interference control in autism spectrum disorders: two meta-analyses. Autism Res (2014b) 7(4):407-20. doi: 10.1002/aur.1369

69. Stroop JR. Studies of interference in serial verbal reactions. J Exp Psychol (1935) 18:643-62. doi: 10.1037/h0054651>

70. Gomez P, Ratcliff R, Perea M. A model of the go/no-go task. J Exp Psychol Gen (2007) 136(3):389-413.

71. Burgess PW, Shallice T. Bizarre responses, rule detection and frontal lobe lesions. Cortex (1996) 32:241-59.

72. Eriksen CW. The flankers task and response competition: a useful tool for investigating a variety of cognitive problems. Vis Cognit (1995) 2(2-3):101-18.

73. Mielicki MK, Koppel RH, Valencia G, Wiley J. Measuring working memory capacity with the letter-number sequencing task: advantages of visual administration. Appl Cognitive Psychol (2018) 32(6):805-14. doi: 10.1002/ acp.3468

74. Wechsler D. Wechsler Memory Scale - Third Edition. San Antonio, Texas: The Psychological Corporation (1997). doi: 10.1037/t49755-000

75. Kane MJ, Conway ARA, Miura TK, Colflesh GJH. Working memory, attention control, and the n-back task: a question of construct validity. J Exp Psychol (2007) 33(3):615-22. doi: 10.1037/0278-7393.33.3.615

76. Zelazo PD, Carlson SM. Hot and cool executive function in childhood and adolescence: development and plasticity. Child Dev Perspect (2012) 6(4):35460. doi: 10.1111/j.1750-8606.2012.00246.x

77. Bechara A, Damasio AR, Damasio H, Anderson SW. Insensitivity to future consequences following damage to human prefrontal cortex. Cognition (1994) 50(1):7-15. doi: 10.1016/0010-0277(94)90018-3

78. Goldstein S, Naglieri JA, Princiotta D, Otero TM. Introduction: a history of executive functioning as a theoretical and clinical construct. In: Goldstein
S, Naglieri JA, editors. Handbook of executive functioning. New York, NY: Springer New York (2014). p. 3-12. doi: 10.1007/978-1-4614-8106-5_1

79. Baddeley A. Working memory. Clarendon Press: Oxford (1986).

80. Shallice T, Burgess Paul W. Deficits in strategy application following frontal lobe damage in man. Brain (1991) 114:727-41. doi: 10.1093/brain/114.2.727

81. Diamond A. Executive functions. Annu Rev Psychol (2013) 64:135-68. doi: 10.1146/annurev-psych-113011-143750

82. Miyake A, Friedman NP. The nature and organization of individual differences in executive functions: four general conclusions. Curr Direct Psychol Sci (2012) 21(1):8-14. doi: 10.1177/0963721411429458

83. Zelazo PD, Müller U. Executive function in typical and atypical development. In: Blackwell handbook of childhood cognitive development. Malden: Blackwell Publishing (2002). p. 445-69. doi: 10.1002/9780470996652.ch20

84. Perone S, Almy B, Zelazo PD. Chapter 11-Toward an understanding of the neural basis of executive function development. In: The neurobiology of brain and behavioral development. San Diego, United States: Academic Press (2018). p. 291-314. doi: 10.1016/B978-0-12-804036-2.00011-X

85. Kouklari E-C, Thompson T, Monks CP, Tsermentseli S. Hot and cool executive function and its relation to theory of mind in children with and without autism spectrum disorder. J Cognit Dev (2017) 18:399-418. doi: $10.1080 / 15248372.2017 .1339708$

86. Zimmerman DL, Ownsworth T, O’Donovan A, Roberts J, Gullo MJ. Independence of hot and cold executive function deficits in high-functioning adults with autism spectrum disorder. Front Hum Neurosci (2016) 10(24). doi: $10.3389 /$ fnhum.2016.00024

87. Henri-Bhargava A, Stuss DT, Freedman M. Clinical assessment of prefrontal lobe functions. CONTINUUM: Lifelong Lear Neurol (2018) 24(3):704-26. doi: 10.1212/CON.0000000000000609

88. Barkley R,A. Executive functions: what they are, why they work and why they evolved. 72 Spring Street, New York, NY 10012: The Guildford Press (2012).

89. Libero LE, DeRamus TP, Lahti AC, Deshpande G, Kana RK. Multimodal neuroimaging based classification of autism spectrum disorder using anatomical, neurochemical, and white matter correlates. Cortex (2015) 66:46-59. doi: 10.1016/j.cortex.2015.02.008

90. Chmielewski WX, Beste C. Action control processes in autism spectrum disorder-insights from a neurobiological and neuroanatomical perspective. Prog Neurobiol (2015) 124:49-83. doi: 10.1016/j.pneurobio.2014.11.002

91. Cazalis F, Valabrègue R, Pélégrini-Issac M, Asloun S, Robbins TW, Granon S. Individual differences in prefrontal cortical activation on the Tower of London planning task: implication for effortful processing. Eur J Neurosci (2003) 17(10):2219-25. doi: 10.1046/j.1460-9568.2003.02633.x

92. Taylor MJ, Donner EJ, Pang EW. fMRI and MEG in the study of typical and atypical cognitive development. Neurophysiol Clinique/Clin Neurophysiol (2012) 42(1):19-25. doi: 10.1016/j.neucli.2011.08.002

93. Logue SF, Gould TJ. The neural and genetic basis of executive function: attention, cognitive flexibility, and response inhibition. Pharmacol Biochem Behav (2014) 123:45-54. doi: 10.1016/j.pbb.2013.08.007

94. Ajram LA, Pereira AC, Durieux AMS, Velthius HE, Petrinovic MM, McAlonan GM. The contribution of $[1 \mathrm{H}]$ magnetic resonance spectroscopy to the study of excitation-inhibition in autism. Prog Neuro-Psychopharmacol Biol Psychiatry (2019) 89:236-44. doi: 10.1016/j.pnpbp.2018.09.010

95. de la Vega A, Brown MS, Snyder HR, Singel D, Munakata Y, Banich MT. Individual differences in the balance of GABA to glutamate in $\mathrm{pFC}$ predict the ability to select among competing options. J Cognit Neurosci (2014) 26(11):2490-502. doi: 10.1162/jocn_a_00655

96. Leung RC, Zakzanis KK. Brief report: Cognitive flexibility in autism spectrum disorders: a quantitative review. J Autism Dev Disord (2014) 44(10):2628-45. doi: 10.1007/s10803-014-2136-4

97. Wang Y, Zhang Y-b, Liu L-l, Cui J-f, Wang J, Shum DHK, et al. A metaanalysis of working memory impairments in autism spectrum disorders. Neuropsychol Rev (2017) 27(1):46-61. doi: 10.1007/s11065-016-9336-y

98. van den Bergh SF, Scheeren AM, Begeer S, Koot HM, Geurts HM. Age related differences of executive functioning problems in everyday life of children and adolescents in the autism spectrum. J Autism Dev Disord (2014) 44(8):1959-71. doi: 10.1007/s10803-014-2071-4

99. Poon K. Hot and cool executive functions in adolescence: development and contributions to important developmental outcomes. Front Psychol (2018) 8(2311). doi: $10.3389 /$ fpsyg.2017.02311 
100. Kouklari E-C, Tsermentseli S, Monks CP. Hot and cool executive function in children and adolescents with autism spectrum disorder: cross-sectional developmental trajectories. Child Neuropsychol (2018b) 24(8):1088-114. doi: 10.1080/09297049.2017.1391190

101. Maximo JO, Cadena EJ, Kana RK. The implications of brain connectivity in the neuropsychology of autism. Neuropsychol Rev (2014) 24(1):16-31. doi: 10.1007/s11065-014-9250-0

102. Abbott AE, Nair A, Keown CL, Datko M, Jahedi A, Fishman I, et al. Patterns of atypical functional connectivity and behavioral links in autism differ between default, salience, and executive networks. Cereb Cortex (2016) 26(10):4034-45. doi: 10.1093/cercor/bhv191

103. Maximo JO, Kana RK. Aberrant "deep connectivity" in autism: a corticosubcortical functional connectivity magnetic resonance imaging study. Autism Res (2019) 12(3):384-400. doi: 10.1002/aur.2058

104. Koshino H, Kana RK, Keller TA, Cherkassky VL, Minshew NJ, Just MA. fMRI investigation of working memory for faces in autism: visual coding and underconnectivity with frontal areas. Cereb Cortex (2008) 18(2):289-300. doi: 10.1093/cercor/bhm054

105. Kana RK, Keller TA, Minshew NJ, Just MA. Inhibitory control in highfunctioning autism: decreased activation and underconnectivity in inhibition networks. Biol Psychiatry (2007) 62(3):198-206. doi: 10.1016/j. biopsych.2006.08.004

106. Braden BB, Smith CJ, Thompson A, Glaspy TK, Wood E, Vatsa D, et al. Executive function and functional and structural brain differences in middle-age adults with autism spectrum disorder. Autism Res (2017) 10(12):1945-59. doi: 10.1002/aur.1842

107. Rubenstein JLR, Merzenich MM. Model of autism: increased ratio of excitation/inhibition in key neural systems. Genes Brain Behav (2003) 2(5):255-67. doi: 10.1034/j.1601-183X.2003.00037.x

108. Al-Otaish H, Al-Ayadhi L, Bjorklund G, Chirumbolo S, Urbina MA, El-Ansary A. Relationship between absolute and relative ratios of glutamate, glutamine and GABA and severity of autism spectrum disorder. Metabol Brain Dis (2018) 33(3):843-54. doi: 10.1007/s11011-018-0186-6

109. Hegarty JP, 2nd, Weber DJ, Cirstea CM, Beversdorf DQ. Cerebro-cerebellar functional connectivity is associated with cerebellar excitation-inhibition balance in autism spectrum disorder. J Autism Dev Disord (2018) 48(10):3460-73. doi: 10.1007/s10803-018-3613-y

110. Cellot G, Cherubini E. GABAergic signaling as therapeutic target for autism spectrum disorders. Front Pediatrics (2014) 2(70). doi: 10.3389/ fped.2014.00070

111. Porges EC, Woods AJ, Edden RAE, Puts NAJ, Harris AD, Chen H, et al. Frontal gamma-aminobutyric acid concentrations are associated with cognitive performance in older adults. Biol Psychiatry Cogn Neurosci Neuroimaging (2017) 2(1):38-44. doi: 10.1016/j.bpsc.2016.06.004

112. Naaijen J, Bralten J, Poelmans G, Consortium I, Glennon JC, Franke B, et al. Glutamatergic and GABAergic gene sets in attention-deficit/hyperactivity disorder: association to overlapping traits in ADHD and autism. Transl Psychiatry (2017) 7(1):e999-9. doi: 10.1038/tp.2016.273

113. Ajram LA, Horder J, Mendez MA, Galanopoulos A, Brennan LP, Wichers $\mathrm{RH}$, et al. Shifting brain inhibitory balance and connectivity of the prefrontal cortex of adults with autism spectrum disorder. Transl Psychiatry (2017) 7:e1137. doi: 10.1038/tp.2017.104

114. DeVon HA, Block ME, Moyle-Wright P, Ernst DM, Hayden SJ, Lazzara DJ, et al. A psychometric toolbox for testing validity and reliability. J Nurs Scholarship (2007) 39(2):155-64. doi: 10.1111/j.1547-5069.2007.00161.x

115. Heaton RK, Chelune GJ, Talley JL, Kay GG, Curtis G. Wisconsin Card Sorting Test (WCST) manual: revised and expanded. Psychological Assessment Resources Inc: Odessa (1993).

116. Roth RM, Isquith PK, Gioia G. BRIEF-A: Behavior Rating Inventory of Executive Function-Adult Version. FL 33549, PAR: Lutz (2005).

117. Burgess PW, Alderman N, Forbes C, Costello A, M-A.Coates L, Dawson DR, et al. The case for the development and use of "ecologically valid" measures of executive function in experimental and clinical neuropsychology. $J$ Int Neuropsychol Soc (2006) 12(2):194-209. doi: 10.1017/S1355617706060310

118. Kenworthy L, Yerys BE, Anthony LG, Wallace GL. Understanding executive control in autism spectrum disorders in the lab and in the real world. Neuropsychol Rev (2008) 18(4):320-38. doi: 10.1007/s11065-008-9077-7
119. Korkman M, Kemp SL, Kirk U. Effects of age on neurocognitive measures of children ages 5 to 12: a cross-sectional study on 800 children from the United States. Dev Neuropsychol (2001) 20(1):331-54. doi: 10.1207/ S15326942DN2001_2

120. De Luca CR, Leventer RJ. Developmental trajectories of executive functions across the lifespan. In: Executive functions and the frontal lobes. New York: Psychology Press (2010). p. 57-90.

121. Ozonoff S, McEvoy RE. A longitudinal study of executive function and theory of mind development in autism. Dev Psychopathol (2008) 6(3):41531. doi: $10.1017 /$ S0954579400006027

122. O'Hearn K, Asato M, Ordaz S, Luna B. Neurodevelopment and executive function in autism. Dev Psychopathol (2008) 20(4):1103-32. doi: 10.1017/ S0954579408000527

123. Liss M, Fein D, Allen D, Dunn M, Feinstein C, Morris R, et al. Executive functioning in high-functioning children with autism. J Child Psychol Psychiatry Allied Disciplines (2001) 42(2):261-70. doi: 10.1017/ S0021963001006679

124. Chiang H-M, Tsai LY, Cheung YK, Brown A, Li H. A meta-analysis of differences in IQ profiles between individuals with Asperger's disorder and high-functioning autism. J Autism Dev Disord (2014) 44(7):1577-96. doi: 10.1007/s10803-013-2025-2

125. American Psychiatric Association. Diagnostic and statistical manual of mental disorders. Washington, DC: American Psychiatric Association (1980).

126. Mackinlay R, Charman T, Karmiloff-Smith A. High functioning children with autism spectrum disorder: a novel test of multitasking. Brain Cogn (2006) 61(1):14-24. doi: 10.1016/j.bandc.2005.12.006

127. Nakahachi T, Iwase M, Takahashi H, Honaga E, Sekiyama R, Ukai S, et al. Discrepancy of performance among working memory-related tasks in autism spectrum disorders was caused by task characteristics, apart from working memory, which could interfere with task execution. Psychiatry Clin Neurosci (2006) 60(3):312-8. doi: 10.1111/j.1440-1819.2006.01507.x

128. Verte S, Geurts HM, Roeyers H, Oosterlaan J, Sergeant JA. Executive functioning in children with an autism spectrum disorder: can we differentiate within the spectrum? J Autism Dev Disord (2006) 36(3):351-72. doi: 10.1007/s10803-006-0074-5

129. Yerys BE, Wallace GL, Harrison B, Celano MJ, Giedd JN, Kenworthy LE. Setshifting in children with autism spectrum disorders: reversal shifting deficits on the Intradimensional/Extradimensional Shift Test correlate with repetitive behaviors. Autism (2009a) 13(5):523-38. doi: 10.1177/1362361309335716

130. Ozonoff S, Pennington BF, Rogers SJ. Executive function deficits in highfunctioning autistic individuals: relationship to theory of mind. $J$ Child Psychol Psychiatry (1991a) 32(7):1081-105. doi: 10.1111/j.1469-7610.1991. tb00351.x

131. Goldberg MC, Mostofsky SH, Cutting LE, Mahone EM, Astor BC, Denckla $\mathrm{MB}$, et al. Subtle executive impairment in children with autism and children with ADHD. J Autism Dev Disord (2005) 35(3):279-93. doi: 10.1007/ s10803-005-3291-4

132. Lam YG. Re-examining the cognitive phenotype in autism: a study with young Chinese children. Res Dev Disabilities (2013) 34:4591-8. doi: 10.1016/j.ridd.2013.09.039

133. Montgomery JM, Stoesz BM, McCrimmon AW. Emotional intelligence, theory of mind, and executive functions as predictors of social outcomes in young adults with Asperger syndrome. Focus Autism Dev Disabilities (2013) 28(1):4-13. doi: 10.1177/1088357612461525

134. Prior M, Hoffmann W. Brief report: Neuropsychological testing of autistic children through an exploration with frontal lobe tests. J Autism Dev Disord (1990) 20(4):581-90. doi: 10.1007/BF02216063

135. Christ SE, Holt DD, White DA, Green L. Inhibitory control in children with autism spectrum disorder. J Autism Dev Disord (2007) 37(6):1155-65. doi: 10.1007/s10803-006-0259-y

136. Nyden A, Hagberg B, Gousse V, Rastam M. A cognitive endophenotype of autism in families with multiple incidence. Res Autism Spectr Disord (2011) 5(1):191-200. doi: 10.1016/j.rasd.2010.03.010

137. Szatmari P, Tuff L, Finlayson MAJ, Bartolucci G. Asperger's syndrome and autism: neurocognitive aspects. J Am Acad Child Adolesc Psychiatry (1990) 29(1):130-6. doi: 10.1097/00004583-199001000-00021 
138. Ozonoff S, McEvoy RE. A longitudinal study of executive function and theory of mind development in autism. Dev Psychopathol (1994) 6:415-31. doi: $10.1017 /$ S0954579400006027

139. Bennetto L, Pennington BF, Rogers SJ. Intact and impaired memory functions in autism. Child Dev (1996) 67(4):1816-35. doi: 10.1111/j.14678624.1996.tb01830.x

140. Toplak ME, West RF, Stanovich KE. Practitioner review: do performancebased measures and ratings of executive function assess the same construct? J Child Psychol Psychiatry (2013) 54(2):131-43. doi: 10.1111/jcpp.12001

141. Toplak ME, Bucciarelli SM, Jain U, Tannock R. Executive functions: performance-based measures and the Behavior Rating Inventory of Executive Function (BRIEF) in adolescents with attention deficit/ hyperactivity disorder (ADHD). Child Neuropsychol (2008) 15(1):53-72. doi: 10.1080/09297040802070929

142. Gioia GA, Isquith PK, Kenworthy L, Barton RM. Profiles of everyday executive functions in acquired and developmental disorders. Child Neuropsychol (2002) 8(2):121-37. doi: 10.1076/chin.8.2.121.8727

143. Ozonoff S. Reliability and validity of the Wisconsin Card Sorting Test in studies of autism. Neuropsychol (1995) 9(4):491-500. doi: 10.1037//0894-4105.9.4.491

144. Williams D, Jarrold C. Assessing planning and set-shifting abilities in autism: are experimenter-administered and computerised versions of tasks equivalent? Autism Res (2013) 6(6):461-7. doi: 10.1002/aur.1311

145. Joseph RM, Keehn B, Connolly C, Wolfe JM, Horowitz TS. Why is visual search superior in autism spectrum disorder? Dev Sci (2009) 12(6):1083-96. doi: 10.1111/j.1467-7687.2009.00855.x

146. Loomes R, Hull L, Mandy WPL. What is the male-to-female ratio in autism spectrum disorder? A systematic review and meta-analysis. J Am Acad Child Adolesc Psychiatry (2017) 56(6):466-74. doi: 10.1016/j.jaac.2017.03.013

147. Skuse DH. Imprinting, the X-chromosome, and the male brain: explaining sex differences in the liability to autism. Pediatr Res (2000) 47:9. doi: 10.1203/00006450-200001000-00006

148. Baron-Cohen S, Knickmeyer RC, Belmonte MK. Sex differences in the brain: implications for explaining autism. Science (2005) 310(5749):819-23. doi: 10.1126/science.1115455

149. Frazier TW, Georgiades S, Bishop SL, Hardan AY. Behavioral and cognitive characteristics of females and males with autism in the Simons Simplex Collection. J Am Acad Child Adolesc Psychiatry (2014) 53(3):329-340.e323. doi: 10.1016/j.jaac.2013.12.004

150. Ferri SL, Abel T, Brodkin ES. Sex differences in autism spectrum disorder: a review. Curr Psychiatry Rep (2018) 20(2):9. doi: 10.1007/s11920-018-0874-2

151. Lai M-C, Lombardo MV, Ruigrok ANV, Chakrabarti B, Wheelwright SJ, Auyeung B, et al. Cognition in males and females with autism: similarities and differences. PLOS ONE (2012) 7(10):e47198. doi: 10.1371/journal. pone. 0047198

152. Memari AH, Ziaee V, Shayestehfar M, Ghanouni P, Mansournia MA, Moshayedi P. Cognitive flexibility impairments in children with autism spectrum disorders: links to age, gender and child outcomes. Res Dev Disabilities (2013) 34(10):3218-25. doi: 10.1016/j.ridd.2013.06.033

153. Lehnhardt F-G, Falter CM, Gawronski A, Pfeiffer K, Tepest R, Franklin J, et al. Sex-related cognitive profile in autism spectrum disorders diagnosed late in life: implications for the female autistic phenotype. J Autism Dev Disord (2016) 46(1):139-54. doi: 10.1007/s10803-015-2558-7

154. Kiep M, Spek AA. Executive functioning in men and women with an autism spectrum disorder. Autism Res (2017) 10(5):940-8. doi: 10.1002/aur.1721

155. Lai M-C, Lombardo MV, Ruigrok AN, Chakrabarti B, Auyeung B, Szatmari P, et al. Quantifying and exploring camouflaging in men and women with autism. Autism (2017b) 21(6):690-702. doi: 10.1177/1362361316671012

156. Wallace GL, Yerys BE, Peng C, Dlugi E, Anthony LG, Kenworthy L. Chapter three-Assessment and treatment of executive function impairments in autism spectrum disorder: an update. In: Hodapp RM, Fidler DJ, editors. International Review of Research in Developmental Disabilities. vol. 51 Cambridge, Massachusetts, United States: Academic Press (2016b). p. 85-122. doi: 10.1016/bs.irrdd.2016.07.004

157. Park SH, Song YJC, Demetriou EA, Pepper KL, Norton A, Thomas EE, et al. Disability, functioning, and quality of life among treatment-seeking young autistic adults and its relation to depression, anxiety, and stress. Autism (2019) 23(7):1675-86. doi: 10.1177/1362361318823925
158. Eysenck MW, Derakshan N. New perspectives in attentional control theory. Pers Individual Diff (2011) 50(7):955-60. doi: 10.1016/j. paid.2010.08.019

159. Liston C, McEwen BS, Casey BJ. Psychosocial stress reversibly disrupts prefrontal processing and attentional control. Proc Natl Acad Sci of U S A (2009) 106(3):912-7. doi: 10.1073/pnas.0807041106

160. Eysenck M, Payne S, Derakshan N. Trait anxiety, visuospatial processing, and working memory. Cogn Emotion (2005) 19(8):1214-28. doi: 10.1080/ 02699930500260245

161. Salthouse TA. How general are the effects of trait anxiety and depressive symptoms on cognitive functioning? Emotion (2012) 12(5):1075. doi: $10.1037 / \mathrm{a} 0025615$

162. Visu-Petra L, Miclea M, Visu-Petra G. Individual differences in anxiety and executive functioning: a multidimensional view. Int J Psychol (2013) 48(4):649-59. doi: 10.1080/00207594.2012.656132

163. Ursache A, Raver CC. Trait and state anxiety: relations to executive functioning in an at-risk sample. Cogn Emotion (2014) 28(5):845-55. doi: 10.1080/02699931.2013.855173

164. Hollocks MJ, Jones CRG, Pickles A, Baird G, Happé F, Charman T, et al. The association between social cognition and executive functioning and symptoms of anxiety and depression in adolescents with autism spectrum disorders. Autism Res (2014) 7(2):216-28. doi: 10.1002/aur.1361

165. Feczko E, Balba NM, Miranda-Dominguez O, Cordova M, Karalunas SL, Irwin L, et al. Subtyping cognitive profiles in autism spectrum disorder using a functional random forest algorithm. Neuroimage (2018) 172:674-88. doi: 10.1016/j.neuroimage.2017.12.044

166. Dajani DR, Llabre MM, Nebel MB, Mostofsky SH, Uddin LQ. Heterogeneity of executive functions among comorbid neurodevelopmental disorders. Sci Rep (2016) 6:36566. doi: 10.1038/srep36566

167. Dajani DR, Burrows CA, Nebel MB, Mostofsky SH, Gates KM, Uddin LQ. Parsing heterogeneity in autism spectrum disorder and attention-deficit/ hyperactivity disorder with individual connectome mapping. bioRxiv (2018) 490672. doi: 10.1101/490672

168. Rommelse NNJ, Geurts HM, Franke B, Buitelaar JK, Hartman CA. A review on cognitive and brain endophenotypes that may be common in autism spectrum disorder and attention-deficit/hyperactivity disorder and facilitate the search for pleiotropic genes. Neurosci Biobehav Rev (2011) 35(6):136396. doi: 10.1016/j.neubiorev.2011.02.015

169. Cornblatt BA, Malhotra AK. Impaired attention as an endophenotype for molecular genetic studies of schizophrenia. Am J Med Gen (2001) 105(1):11-5. doi: 10.1002/1096-8628(20010108)105:1<11::AID-AJMG1045>3.3.CO;2-7

170. Gottesman II, Gould TD. The endophenotype concept in psychiatry: etymology and strategic intentions. Am J Psychiatry (2003) 160(4):636-45. doi: 10.1176/appi.ajp.160.4.636

171. Turner M. Towards an executive dysfunction account of repetitive behaviour in autism. In: Autism as an executive disorder. New York, NY, US: Oxford University Press (1997). p. 57-100.

172. Turner M. Annotation: repetitive behaviour in autism: a review of psychological research. J Child Psychol Psychiatry Allied Disciplines (1999) 40(6):839-49. doi: 10.1017/S0021963099004278

173. Ozonoff S, Rogers SJ, Pennington BF. Asperger's syndrome: evidence of an empirical distinction from high-functioning autism. J Child Psychol Psychiatry Allied Disciplines (1991b) 32(7):1107-22. doi: 10.1111/j.14697610.1991.tb00352.x

174. Hughes C, Russell J. Autistic children's difficulty with mental disengagement from an object: its implications for theories of autism. Dev Neuropsychol (1993) 29(3):498-510. doi: 10.1037//0012-1649.29.3.498

175. Kenworthy L, Black DO, Harrison B, della Rosa A, Wallace GL. Are executive control functions related to autism symptoms in highfunctioning children? Child Neuropsychol (2009) 15(5):425-40. doi: $10.1080 / 09297040802646983$

176. Pellicano E. Links between theory of mind and executive function in young children with autism: clues to developmental primacy. Dev Neuropsychol (2007) 43(4):974-90. doi: 10.1037/0012-1649.43.4.974

177. Mazza M, Mariano M, Peretti S, Masedu F, Pino MC, Valenti M. The role of theory of mind on social information processing in children with autism spectrum disorders: a mediation analysis. J Autism Dev Disord (2017) 47(5):1369-79. doi: 10.1007/s10803-017-3069-5 
178. Pepper KL, Demetriou EA, Park SH, Song YC, Hickie IB, Cacciotti-Saija C, et al. Autism, early psychosis, and social anxiety disorder: understanding the role of social cognition and its relationship to disability in young adults with disorders characterized by social impairments. Transl Psychiatry (2018) 8(1):233. doi: 10.1038/s41398-018-0282-8

179. McEvoy RE, Rogers SJ, Pennington BF. Executive function and social communication deficits in young autistic children.J Child Psychol Psychiatry (1993) 34(4):563-78. doi: 10.1111/j.1469-7610.1993.tb01036.x

180. Jurado MB, Rosselli M. The elusive nature of executive functions: a review of our current understanding. Neuropsychol Rev (2007) 17(3):213-33. doi: $10.1007 / \mathrm{s} 11065-007-9040-\mathrm{Z}$

181. Lien VE, Bart B, Nele C, Hilde P, Jean S, Johan W, et al. Executive functioning and local-global visual processing: candidate endophenotypes for autism spectrum disorder? J Child Psychol Psychiatry (2017) 58(3):258-69. doi: 10.1111/jcpp.12637

182. Cuthbert BN, Insel TR. Toward the future of psychiatric diagnosis: the seven pillars of RDoC. BMC Med (2013) 11(1):126. doi: 10.1186/1741-7015-11-126
183. Casey BJ, Oliveri ME, Insel T. A neurodevelopmental perspective on the Research Domain Criteria (RDoC) framework. Biol Psychiatry (2014) 76(5):350-3. doi: 10.1016/j.biopsych.2014.01.006

184. Mittal VA, Wakschlag LS. Research domain criteria (RDoC) grows up: strengthening neurodevelopment investigation within the RDoC framework. J Affect Disord (2017) 216:30-5. doi: 10.1016/j.jad.2016.12.011

Conflict of Interest: The authors declare that the research was conducted in the absence of any commercial or financial relationships that could be construed as a potential conflict of interest.

Copyright (C) 2019 Demetriou, DeMayo and Guastella. This is an open-access article distributed under the terms of the Creative Commons Attribution License (CC $B Y)$. The use, distribution or reproduction in other forums is permitted, provided the original author(s) and the copyright owner(s) are credited and that the original publication in this journal is cited, in accordance with accepted academic practice. No use, distribution or reproduction is permitted which does not comply with these terms. 